NBER WORKING PAPER SERIES

\title{
QUALITATIVE EASING: HOW IT WORKS AND WHY IT MATTERS
}

\author{
Roger E.A. Farmer \\ Working Paper 18421 \\ http://www.nber.org/papers/w18421
NATIONAL BUREAU OF ECONOMIC RESEARCH 1050 Massachusetts Avenue Cambridge, MA 02138
September 2012

I would like to thank C. Roxanne Farmer for her editorial assistance. The views expressed herein are those of the author and do not necessarily reflect the views of the National Bureau of Economic Research.

NBER working papers are circulated for discussion and comment purposes. They have not been peerreviewed or been subject to the review by the NBER Board of Directors that accompanies official NBER publications.

(C) 2012 by Roger E.A. Farmer. All rights reserved. Short sections of text, not to exceed two paragraphs, may be quoted without explicit permission provided that full credit, including $(\mathbb{C}$ notice, is given to the source. 
Qualitative Easing: How it Works and Why it Matters

Roger E.A. Farmer

NBER Working Paper No. 18421

September 2012, Revised December 2012

JEL No. E0,E5,E52,E62

\begin{abstract}
$\underline{\text { ABSTRACT }}$
This paper is about the effectiveness of qualitative easing; a government policy that is designed to mitigate risk through central bank purchases of privately held risky assets and their replacement by government debt, with a return that is guaranteed by the taxpayer. Policies of this kind have recently been carried out by national central banks, backed by implicit guarantees from national treasuries. I construct a general equilibrium model where agents have rational expectations and there is a complete set of financial securities, but where agents are unable to participate in financial markets that open before they are born. I show that a change in the asset composition of the central bank's balance sheet will change equilibrium asset prices. Further, I prove that a policy in which the central bank stabilizes fluctuations in the stock market is Pareto improving and is costless to implement.
\end{abstract}

\author{
Roger E.A. Farmer \\ UCLA \\ Department of Economics \\ Box 951477 \\ Los Angeles, CA 90095-1477 \\ and NBER \\ rfarmer@econ.ucla.edu
}




\section{Introduction}

Central banks throughout the world have recently engaged in two kinds of unconventional monetary policies: quantitative easing (QE), which is "an increase in the size of the balance sheet of the central bank through an increase it is monetary liabilities", and qualitative easing (QuaE) which is "a shift in the composition of the assets of the central bank towards less liquid and riskier assets, holding constant the size of the balance sheet." ${ }^{1}$

I have made the case, in a recent series of books and articles, (Farmer, 2006, 2010a,b,c,d, 2012, 2013), that qualitative easing can stabilize economic activity and that a policy of this kind will increase economic welfare. In this paper I provide an economic model that shows how qualitative easing works and why it matters.

Because qualitative easing is conducted by the central bank, it is often classified as a monetary policy. But because it adds risk to the public balance sheet that is ultimately borne by the taxpayer, QuaE is better thought of as a fiscal or quasi-fiscal policy (Buiter, 2010). This distinction is important because, in order to be effective, QuaE necessarily redistributes resources from one group of agents to another.

The misclassification of QuaE as monetary policy has led to considerable confusion over its effectiveness and a misunderstanding of the channel by which it operates. For example, in an influential piece that was presented at the 2012 Jackson Hole Conference, Woodford (2012) made the claim that QuaE is unlikely to be effective and, to the extent that it does stimulate economic activity, that stimulus must come through the impact of QuaE on the expectations of financial market participants of future Fed policy actions.

The claim that QuaE is ineffective, is based on the assumption that it has no effect on the distribution of resources, either between borrowers and lenders in the current financial markets, or between current market partic-

\footnotetext{
${ }^{1}$ The quote is from Willem Buiter (2008) who proposed this very useful taxonomy in a piece on his 'Maverecon' Financial Times blog.
} 
ipants and those yet to be born. I will argue here, that that assumption is not a good characterization of the way that QuaE operates, and that QuaE is effective precisely because it alters the distribution of resources by effecting Pareto improving trades that agents are unable to carry out for themselves.

I make the case for qualitative easing by constructing a simple general equilibrium model where agents are rational, expectations are rational and the financial markets are complete. My work differs from most conventional models of financial markets because I make the not unreasonable assumption, that agents cannot participate in financial markets that open before they are born. In this environment, I show that qualitative easing changes asset prices and that a policy where the central bank uses QuaE to stabilize the value of the stock market is Pareto improving and is costless to implement.

My argument builds upon an important theoretical insight due to Cass and Shell (1983), who distinguish between intrinsic uncertainty and extrinsic uncertainty. Intrinsic uncertainty is a random variable that influences the fundamentals of the economy; preferences, technologies and endowments. Extrinsic uncertainty is anything that does not. Cass and Shell refer to extrinsic uncertainty as sunspots. ${ }^{2}$

In this paper, I prove four propositions. First, I show that employment, consumption and the real wage are a function of the amount of outstanding private debt. Second, I prove that the existence of complete insurance markets is insufficient to prevent the existence of equilibria where employment, consumption and the real wage differ in different states, even when all uncertainty is extrinsic. Third, I introduce a central bank and I show that a central bank swap of safe for risky assets will change the relative price of debt and equity. Finally, I prove that a policy of stabilizing the value of the stock market is welfare improving and that it does not involve a cost to the taxpayer in any state of the world.

\footnotetext{
${ }^{2}$ This is quite different from the original usage of the term by Jevons (1878) who developed a theory of the business cycle, driven by fluctuations in agricultural conditions that were ultimately caused by physical sunspot activity.
} 


\section{The portfolio balance view}

Much of the academic discussion concerning the effectiveness of qualitative easing has been conducted in the context of general equilibrium models where rational forward looking agents are able to trade securities in a set of complete financial markets. In this context, central bank asset swaps are irrelevant because the existence of complete markets acts to transfer risk efficiently to those who are most capable of bearing it.

In a complete markets environment, the government cannot remove risk. It can simply transfer that risk from the private balance sheet to the public balance sheet. Since the public balance sheet is ultimately backed by the tax liabilities of the private sector, the risk does not disappear; it is simply relabeled. Rational agents, recognizing this legerdemain on the part of the central bank, will readjust their financial positions to undo the central bank intervention and the change in the central bank's balance sheet will have no influence on realized security prices. In this vision of the world, central bank asset swaps are irrelevant. ${ }^{3}$

The case for the effectiveness of qualitative easing is attributed to Tobin $(1963,1969)$ who argued that private agents form asset demands that are functions of relative asset prices, much as the demands for commodities depend on relative goods prices. Citing papers by Krugman (1998) and Eggertsson and Woodford (2002) where the case is made explicitly, Woodford (2012) argues that this so-called portfolio balance view is invalid, and, if central bank asset purchases are to be effective, their effectiveness must rely on their ability to alter the public's expectations of future central bank policies. In Woodford's view, qualitative easing is a way of signalling to the public that the Fed intends to act differently in future states that will occur once the economy exits the zero lower bound. ${ }^{4}$

\footnotetext{
${ }^{3}$ This view is sometimes referred to as Wallace neutrality, since it relies on arguments made by Neil Wallace (1981).

${ }^{4}$ That argument is not without merit and I have presented a simple model in my own
} 
But although central bank asset purchases cannot influence relative prices in theory, there is a growing empirical literature that finds significant effects of QuaE on asset prices in practice. ${ }^{5}$ The case is summarized by Joseph Gagnon, who has made a number of notable contributions to this literature.

The evidence shows that Fed purchases affected the prices of a broad range of assets at once, not just the prices of those bonds being purchased directly. ... These effects of Fed asset purchases are fully consistent with what would have been expected based on data from before the financial crisis, and with the portfolio balance view. Gagnon (2012).

There is an apparent disconnect. According to modern economic theory, economic agents are rational and hold rational expectations of future prices. If markets are complete and frictionless, conventional economic theory predicts that central bank open market swaps of risky securities for safe securities cannot influence asset prices. But the evidence demonstrates that central bank asset purchases do influence asset prices and that the effects of open market operations in risky securities "are consistent with the portfolio balance view".

When the facts conflict with the theory, the wise course is to seek a way to amend the theory in a way that maintains those assumptions that have proven successful at explaining other aspects of economic behavior. In my view, these include the assumptions of rational agents, rational expectations and complete financial markets. In this paper I maintain all of these assump-

work (Farmer, 2013) that shows how and why qualitative easing can back up a change in the policy rule once the interest rate has reached its zero lower bound. But although qualitative easing may have effects of this kind, the ability of QuaE to influence expectations is not the primary reason why it is effective.

${ }^{5}$ Examples of recent empirical papers that find a significant effect of Fed asset purchases on asset prices include Krishnamurthy and Vissing-Jorgensen (2011); Gagnon, Raskin, Remache, and Sack (2011); D'Amico and King (2010); Neely (2010); Li and Wei (2012), and Hamilton and $\mathrm{Wu}(2012)$. 
tions. But as in Cass and Shell (1983), I do not permit agents to trade in financial markets that open before they are born.

In this environment, I show that 1) a central bank that takes risk onto its balance sheet, financed by issuing debt, can increase welfare and 2) there is an optimal policy which is self-financing and does not result in a cost to the taxpayer in any state of nature. When all uncertainty is extrinsic, the optimal policy is for the central bank to stabilize the stock market so that the return to the stock market is equal, in every state, to the return to a one-period government bond.

\section{Elements of a successful theory}

This paper presents an example of a general equilibrium model where qualitative easing is effective. The example is designed to illustrate the mechanism involved in my argument. It is not meant to be a realistic description of an actual economy. ${ }^{6}$

The argument in favor of government intervention to stabilize asset prices is based on the idea that 'sunspots matter'. At a minimum, an example of a general equilibrium model that displays this property must have the following characteristics.

- There must be at least two periods, one period in which financial assets are traded and one in which uncertainty is realized.

- There must be at least two types of agents that participate in financial markets. This assumption is important because the goal of the argu-

\footnotetext{
${ }^{6}$ For a realistic description of an actual economy, the reader is referred to Farmer, Nourry, and Venditti (2012) which explores implications of the case for central bank intervention in an infinite horizon model. We show, in that paper, that sunspots can have large effects on the financial markets in an economy where the degree of incomplete participation is calibrated to match realistic birth and death probabilities. These effects are large because they influence the entire future path of interest rates, and that affects the human wealth, not only of the as yet unborn, but also of all of the households currently alive.
} 
ment is to show how sunspots can interfere with optimal risk sharing between agents.

- There must be at least two commodities. This is essential because sunspots act by interfering with relative price signals.

- Finally, there must be at least one type of agent that is unable to participate in the financial markets. It is this feature that it is responsible for the failure of complete financial markets to coordinate economic activity effectively.

\section{A one-period environment}

I begin by describing a simple, one-period economy. There is a single good which is produced from labor and capital. ${ }^{7}$ There are three types of agents. Types 1 and 2 each own one unit of labor. Type 3 agents own one unit of capital. Each of the types, 1 and 2 , chooses labor $n_{i}$ and consumption $c_{i}$, to maximize utility

$$
U_{i}=\left(1-\lambda_{i}\right) \log \left(1-n_{i}\right)+\lambda_{i} \log \left(c_{i}\right),
$$

subject to the budget constraint,

$$
w\left(1-n_{i}\right)+p c_{i} \leq w+p A_{i}, \quad i \in\{1,2\}
$$

Here, $w$, and $p$ are the wage and the price of the commodity in units of account and $A_{i}$ is a real financial asset, denominated in units of the consumption commodity, that satisfies the constraint

$$
\sum_{i \in\{1,2\}} A_{i}=0
$$

\footnotetext{
${ }^{7}$ In this example the two goods, required for sunspots to matter, are consumption and leisure.
} 
The solution to the agent's problem is represented by equations (4) and (5).

$$
\begin{aligned}
w\left(1-n_{i}\right) & =\left(1-\lambda_{i}\right)\left(w+p A_{i}\right) \\
p c_{i} & =\lambda_{i}\left(w+p A_{i}\right) .
\end{aligned}
$$

If we solve these equations for $n_{i}$ and $c_{i}$ and add them up over both types, we arrive at the aggregate labor supply and consumption demand equations,

$$
\begin{aligned}
n & =\Lambda+\frac{A}{w / p}, \\
c & =\Lambda \frac{w}{p}+A
\end{aligned}
$$

where

$$
\Lambda=\sum \lambda_{i}, \quad A=\left(\lambda_{1}-\lambda_{2}\right) A_{1}
$$

I assume, without loss of generality, that $\lambda_{1}-\lambda_{2}>0$.

Next I turn to type 3 agents, each of whom owns a unit of capital and operates a technology of the form,

$$
y \leq n^{\alpha}
$$

where $y$ is the output of commodities. Type 3 agents solve the problem

$$
\max \Pi=y-\frac{w}{p} n
$$

subject to (9), and they consume the profits. The first order condition for problem (10) is the expression.

$$
w n=\alpha p y .
$$

A competitive equilibrium for this economy is a price system $\{p, w\}$, a production plan $\{n, y\}$, an allocation $\left\{n^{i}, c^{i}\right\}$ for $i \in\{1,2,3\}$ such that each 
agent optimizes and all markets clear. The solution has the following form,

$$
\begin{array}{rlrl}
n_{i} & =\lambda_{i}-\left(1-\lambda_{i}\right) \frac{A_{i}}{w / p}, & & i=1,2, \\
c_{i} & =\lambda_{i} \frac{w}{p}+\lambda_{i} A_{i}, & i=1,2, \\
c_{i} & =(1-\alpha) n, & & \\
\frac{w}{p} & =\alpha n^{\alpha-1}, & \\
y & =\sum_{i=1,2} c_{i}, & \\
n & =\sum_{i=1,2} n_{i}, & \\
n & =\Lambda+\frac{A}{w / p}, & \\
c & =\Lambda \frac{w}{p}+A .
\end{array}
$$

This system has a unique equilibrium which is computed by finding a real wage $\omega=w / p$ such that the excess demand function for labor,

$$
\zeta(\omega ; A)=\Lambda+\frac{A}{\omega}-\left(\frac{\omega}{\alpha}\right)^{\frac{1}{\alpha-1}}
$$

is equal to zero.

Proposition 1 There are two numbers, $A^{U}>0$ and $A^{L}<0$ such that, for $A \in\left[A^{L}, A^{U}\right]$, the one period economy has an interior equilibrium. There exists a monotonically increasing function $f:\left[A^{L}, A^{U}\right] \rightarrow \bar{W} \subset R_{+}$, such that $\omega=f(A)$ is the equilibrium real wage when type 1 agents have financial assets $A_{1}$, type 2 agents have assets $A_{2}=-A_{1}$ and $A$, is defined as $A=A_{1} /\left(\lambda_{1}-\lambda_{1}\right)$. The equilibrium real wage is the unique solution to the equation,

$$
\xi(w / p ; A)=0 .
$$

The equilibrium values of $\left\{n_{i}, c_{i}\right\},\{n, c\}$ and $y$ are given by the solution to 
equations (12)-(19).

This proposition is proved in Appendix A. The initial conditions of the economy specify that agents of type 1 owe a debt to agents of type 2 . That debt is measured by the variable $A_{1}$. If $A_{1}$ is positive, type 2 agents owe consumption goods to type 1 , if it is negative, type 1 agents owe consumption goods to type 2. Because the two types of agents have different propensities to consume out of wealth, aggregate labor supply, aggregate output and aggregate consumption will be different for different values of private debt.

\section{A two-period environment}

Next, I expand the model by adding an extra period. In period 1, agents of type 1 and 2 meet and they trade financial assets. There are no commodities produced in this period and no consumption. It is critical, for the existence of sunspot equilibria, that type 3 agents are not able to participate in the financial market.

In period 2, there are two possible events; $a$ and $b$. These events have no influence on the physical environment which is identical in the two states of nature. They represent what Cass and Shell (1983) refer to as extrinsic uncertainty or sunspots. But although the physical environment is identical in both states, it is possible that relative prices may change. Type 1 and type 2 agents are able to insure against this uncertainty by trading in a complete set of financial markets that I represent with two Arrow securities, one for each state.

An Arrow security is a promise to pay one unit of the consumption commodity in state $s$ if and only if state $s$ occurs: I denote its price by $Q(s)$. The symbol $\pi_{s}$ is the probability state $s$ occurs and $A_{i}(s)$ is the number of Arrow securities of type $s$ purchased by an agent of type $i$. The symbols $w(s)$ and $p(s)$ are the wage and the price of commodities in state $s$ and $n_{i}(s)$ and $c_{i}(s)$ represent labor supply and consumption in those states. 
Given these assumptions, the problem solved by agent $i$ for $i \in\{1,2\}$ in period 1 , state $s \in\{a, b\}$ is represented by

$$
\max U_{i}=\sum_{s \in\{a, b\}} \pi_{s}\left[\left(1-\lambda_{i}\right) \log \left(1-n_{i}(s)\right)+\lambda_{i} \log \left(c_{i}(s)\right)\right],
$$

such that

$$
\begin{gathered}
\sum_{s \in\{a, b\}} Q(s) A_{i}(s)=0, \\
p(s) c_{i}(s) \leq w(s) n_{i}(s)+p(s) A_{i}(s), \quad s \in\{a, b\} .
\end{gathered}
$$

Equation (23) is the budget constraint in the financial market that opens at date 1 and Equation (24) is the state by state budget constraint that holds in date 2. Since this economy has a complete set of financial markets, each agent faces a single budget constraint that we can find by substituting for $A_{i}(a)$ and $A_{i}(b)$ from Equation (24) into Equation (23). This leads to the expression,

$$
\sum_{s \in\{a, b\}} Q(s)\left[\frac{w(s)}{p(s)} n_{i}(s)-c_{i}(s)\right]=0 .
$$

It will reduce notation somewhat if we define the contingent commodity prices

$$
\hat{p}(s)=Q(s) p(s), \quad \hat{w}(s)=Q(s) w(s) .
$$

Using this notation, let

$$
W=\hat{w}(a)+\hat{w}(b),
$$

be the wealth of an agent, measured in units of account ${ }^{8}$ Using definition (27) and maximizing (22) subject to (25), leads to the following set of first

\footnotetext{
${ }^{8}$ Since I have assumed that agents have equal endowments, $W$ does not depend on $i$. Nothing in my argument depends on this assumption.
} 
order conditions,

$$
\begin{aligned}
\left(1-n_{i}(s)\right) \hat{w}(s) & =\pi_{s}\left(1-\lambda_{i}\right) W \\
c_{i}(s) \hat{p}(s) & =\pi_{s} \lambda_{i} W
\end{aligned}
$$

which must hold for $i \in\{1,2\}$ and $s \in\{a, b\}$. Solving these expressions for $n_{i}(s)$ and $c_{i}(s)$ and aggregating over agents of types 1 and 2 leads to the aggregate labor supply and consumption demand equations,

$$
\begin{aligned}
n(s) & =2-(2-\Lambda) \frac{W}{\hat{w}(s) / \pi_{s}} \\
c(s) & =\Lambda \frac{W}{\hat{p}(s) / \pi_{s}} \\
A_{i}(s) & =\frac{1}{Q(s)}\left(\frac{\hat{w}(s)}{\hat{p}(s)} n_{i}(s)-c_{i}(s)\right),
\end{aligned}
$$

where $\Lambda=\sum \lambda_{i}$.

Because agents of type 3 are not present at date 1 , they are unable to participate in the financial markets. It follows that they solve the same problem as in Section 4 , state by state. Hence, in each state $s \in\{a, b\}$ the following equation holds,

$$
n(s)=\left(\frac{\hat{w}(s) / \hat{p}(s)}{\alpha}\right)^{\alpha-1}
$$

Equation (33) puts the economy on its labor demand curve in each state.

\section{Equilibrium in the two-period environment}

Since the two states are identical, there is an equilibrium in which $A_{i}(s)=0$ for both states and in which all prices and quantities replicate the equilibrium of the one-period economy. The real wage in this equilibrium is the solution 
to the equation,

$$
\zeta(w / p, 0)=0 .
$$

But because the agents of type 3 are not permitted to trade in the financial, markets, there are also many other equilibria. In this economy; sunspots matter.

Proposition 2 Let $A(a)>0$ and $A(b)<0$ be elements of $\left[A^{L}, A^{U}\right]$ where $A^{L}$ and $A^{U}$ are the numbers defined in Proposition 1. There exists an equilibrium of the two period economy where the real wage in state $s$ is a solution to the excess demand equation,

$$
\zeta(\omega(s), A(s))=0, \quad s \in\{a, b\}
$$

and the variables $\left\{n_{i}(s), c_{i}(s)\right\}$ for $s \in\{a, b\}$ and $i \in\{1,2,3\}$ and $\{n, c, y\}$ are given by the solution to equations (12) to (19). The Arrow security prices $Q(a)$ and $Q(b)$ are given by the equations

$$
Q(s)=\frac{1}{A_{1}(s)}\left(\frac{w(s)}{p(s)} n_{1}(s)-c_{1}(s)\right), s \in\{a, b\} .
$$

Proof. The proof follows directly from the existence of equilibrium in each state, which is a consequence of Proposition 1, and the budget constraints, and Equation (32), which leads to the expression for $Q(s)$ in Equation (36).

The existence of sunspot equilibria relies critically on the absence of type 3 agents from the financial markets in period 1 . If those agents were allowed to trade securities, they would solve the problem,

$$
\max U_{3}=\sum_{s \in\{a, b\}} \pi_{s} U(c(s)),
$$


where $U(c(s))$ is an increasing concave function. This problem is subject to the constraints

$$
\sum_{s \in\{a, b\}} Q(s) A_{3}(s)=0
$$

and

$$
c_{3}(s)=(1-\alpha) y(s)+A_{3}(s),
$$

which can be consolidated into the single constraint,

$$
\sum_{s \in\{a, b\}} Q(s)\left[c_{3}(s)-(1-\alpha) y(s)\right]=0
$$

The first order condition for this problem requires that the security prices across the two states should be equal to the ratio of marginal utilities for type 3 agents,

$$
\frac{Q(a)}{Q(b)}=\frac{\pi_{a} U^{\prime}(c(a))}{\pi_{b} U^{\prime}(c(b))} .
$$

Equation (41) provides an additional restriction on real wages across states that rules out sunspot equilibria. This is most easily seen for the case when type 3 agents are risk neutral which implies that $U^{\prime}$ is a constant. In that case it is obvious from Equation (41) that the ratio of the Arrow security prices must equal the ratio of the probabilities,

$$
\frac{Q(a)}{Q(b)}=\frac{\pi_{a}}{\pi_{b}}
$$

But the argument is more general than this and Cass and Shell show that, when utility functions are strictly concave, a sunspot equilibrium cannot exist if all agents are free to participate in the financial markets. ${ }^{9}$

\footnotetext{
${ }^{9}$ They argue as follows. Because the model with complete participation is an example of a finite Arrow-Debreu economy, it must satisfy the first welfare theorem; every competitive equilibrium is Pareto optimal. But agents are risk averse and would prefer a constant allocation to a random allocation with the same expected value. Since all uncertainty is extrinsic, the certain allocation is feasible and it follows that the sunspot allocation cannot be a competitive equilibrium of an economy with complete participation.
} 


\section{Debt and equity}

This section moves away from the abstract notion of an Arrow security to show how a sunspot equilibrium would be supported with the kinds of securities we see in the real world. Since there are only two states, we need only two securities that I will define to be a debt security that pays $(1+i)$ in each state and an equity security that pays $(1+r(s))$ where

$$
r(s)=(1-\alpha) y(s)
$$

The term $r(s)$ is the rental rate of capital and the returns to debt and equity are related to the securities prices by the following equalities,

$$
\begin{gathered}
(1+i)=\frac{1}{Q(a)+Q(b)}, \\
1+r(s)=\frac{1}{Q(s)}, \quad s \in\{a, b\} .
\end{gathered}
$$

To replicate a financial equilibrium with Arrow securities prices $Q(s)$, and net asset positions $A_{i}(s)$, one agent would need to take a long position in debt and a short position in equity. The second agent would reverse these positions.

To replicate a portfolio $\left\{A_{1}(a), A_{1}(b)\right\}$ agent 1 would take the position $\{E,-B\}$ in period 1 and agent 2 would take the position $\{-E, B\}$ where agent 2 lends $B$ units of the consumption good to agent 1 and uses the funds to short $E$ units of equity. Agent 1 borrows $B$ units of the consumption good from agent 2 and uses the funds to buy equity. In period 2, those positions

lead to net transfers between the two agents that correspond to the buying and selling of Arrow securities.

The relationship of the Arrow security holdings to the market payoffs in 
period 2 , is given by the equations,

$$
\begin{aligned}
& A_{1}(a)=(1+r(a)) E+(1+i) B \\
& A_{1}(b)=(1+r(b)) E+(1+i) B .
\end{aligned}
$$

Since the financial markets must clear in period 1 , we have that

$$
B+E=0
$$

which implies that the portfolio positions of type 1 agents at date 2 in states $a$ and $b$ are given by,

$$
A_{1}(a)=-B(i-r(a)), \quad \text { and } \quad A_{1}(b)=-B(i-r(b)),
$$

and the positions of type 2 are given by,

$$
A_{2}(a)=B(i-r(a)), \quad \text { and } \quad A_{2}(b)=B(i-r(b)) .
$$

If state $a$ is a high employment state, and $b$ a low employment state then

$$
r(a)>i, \quad \text { and } \quad r(b)<i \text {. }
$$

It follows that, in state $a$, there is a payment from type 2 to type 1 and, in state $b$ the flow is reversed.

\section{Qualitative easing in theory}

Table 1 illustrates the positions taken by four different agents, those of types 1, 2 and 3 and a government agent that I call a central bank. Initially, I assume that the government agent does not intervene in the asset markets. Although I refer to the government agent as a central bank, this is not a 
monetary economy and the asset market interventions I will describe could equally well be thought of as activities undertaken by the Treasury.

Table 1: Asset Positions in Period 1

\begin{tabular}{|c|c|c|c|c|}
\hline \multicolumn{2}{|c|}{ Type 1} & \multicolumn{3}{|c|}{ Type 2} \\
\hline $\mathrm{A}$ & $\mathrm{L}$ & & $\mathrm{A}$ & $\mathrm{L}$ \\
\hline$E$ & $B$ & & $B$ & $E$ \\
\hline$\frac{\omega}{1+i}$ & $N W_{1}$ & & $\frac{\omega}{1+i}$ & $N W_{2}$ \\
\hline \multicolumn{2}{|c|}{ Type 3} & \multicolumn{3}{|c|}{ C. Bank } \\
\hline $\mathrm{A}$ & $\mathrm{L}$ & $\mathrm{A}$ & & $\mathrm{L}$ \\
\hline 0 & 0 & 0 & & 0 \\
\hline$\frac{\Pi}{1+i}$ & $N W_{i}$ & 0 & $N V$ & $C_{C B}=0$ \\
\hline
\end{tabular}

Table 1 illustrates the idea that type 1 agents borrow to buy equity and type 2 agents short equity to buy debt. The net worth of type 1 and type 2 agents is equal to the net present value of their wage income. The net worth of type 3 agents is equal to the net present value of their rental income. By assumption, the central bank is inactive and has a zero net balance.

Type 1 agents value consumption, as opposed to leisure, more highly than type 2 agents. This is reflected in the assumption that $\lambda_{1}>\lambda_{2}$. Correspondingly, type 2 agents value leisure more highly than consumption and their propensity to consume leisure, as a function of their wealth, is higher than that of type 1 agents. This is reflected in the assumption that $\left(1-\lambda_{2}\right)>\left(1-\lambda_{1}\right)$. 
Table 2: Asset Positions in Period 2 State $s$

\begin{tabular}{|c|c|c|c|c|}
\hline \multicolumn{2}{|c|}{ Туре 1} & \multicolumn{3}{|c|}{ Type 2} \\
\hline $\mathrm{A}$ & $\mathrm{L}$ & & $\mathrm{A}$ & $\mathrm{L}$ \\
\hline$r(s) E$ & $i B$ & & $i B$ & $r(s) E$ \\
\hline$w(s)$ & $N W_{1}(s)$ & & $v(s)$ & $N W_{2}(s)$ \\
\hline \multicolumn{2}{|c|}{ Туре 3} & \multicolumn{3}{|c|}{ C. Bank } \\
\hline A & $\mathrm{L}$ & A & & $\mathrm{L}$ \\
\hline 0 & 0 & 0 & & 0 \\
\hline$\Pi(s)$ & $N W_{3}(s)$ & 0 & $N W$ & $C B(s)=0$ \\
\hline
\end{tabular}

Table 2 shows how the asset positions of the various players are resolved in period 2, after the resolution of uncertainty. By assumption, the real wage is higher in state $a$ than in state $b$. In equilibrium, there is a positive wealth transfer in state $a$ from type 2 agents to type 1 agents. Because $\left(1-\lambda_{2}\right)$ is greater than $\left(1-\lambda_{1}\right)$, a positive wealth transfer from type 2 agents causes that group to reduce their consumption of leisure by more than type 1 agents increase it. In aggregate, less leisure is consumed and aggregate labor supply increases. In state $b$, this effect is reversed.

Since the competitive equilibrium is Pareto inferior, it is natural to ask if there is a policy, conducted by the government agent, that could restore optimality. The reason to be optimistic that an asset market intervention may improve social welfare is that government can potentially replace the role of agents who are unable to participate in asset markets that open before they are born. How would a Pareto improving intervention work? 
Table 3: Asset Positions in Period 1 with CB Intervention

\begin{tabular}{|c|c|c|c|c|}
\hline \multicolumn{2}{|c|}{ Type 1} & \multicolumn{3}{|c|}{ Type 2} \\
\hline $\mathrm{A}$ & $\mathrm{L}$ & & $\mathrm{A}$ & $\mathrm{L}$ \\
\hline $\begin{array}{c}E-\hat{E} \\
\frac{\omega}{1+i}\end{array}$ & $\begin{array}{c}B-\hat{B} \\
N W_{1}\end{array}$ & & $\begin{array}{l}-\hat{B} \\
\frac{\omega}{1+i} \\
\end{array}$ & $\begin{array}{c}E-\hat{E} \\
N W_{2} \\
\end{array}$ \\
\hline \multicolumn{2}{|c|}{ Type 3} & \multicolumn{3}{|c|}{ C. Bank } \\
\hline $\mathrm{A}$ & $\mathrm{L}$ & $\mathrm{A}$ & & $\mathrm{L}$ \\
\hline 0 & 0 & $\hat{E}$ & & $\hat{B}$ \\
\hline$\frac{\Pi}{1+i}$ & $N W_{3}$ & 0 & $N W$ & $C_{C B}=0$ \\
\hline
\end{tabular}

Table 3 illustrates the asset positions of the four agents in period 1 when the central bank intervenes in asset markets by issuing debt, $\hat{B}$ and purchasing equity, $\hat{E}$. The type 1 and type 2 agents hold the residual positions, $E-\hat{E}$ and $B-\hat{B}$.

Table 4 shows how these positions will resolve in period 1 in state $s$. Let us suppose initially, that the equilibrium real wage in each state, $\omega(a)$ and $\omega(b)$ is unchanged by the central bank intervention and so the Arrow security prices are also unchanged. In state $a$, where $r(a)>i$, the bank will make a profit from it's portfolio. In the U.S., central bank profits are returned to the Treasury and I assume that they are returned as lump sum transfers, $T(a)$, to the public.

I assume that there are equal numbers of agents in each group and that one third of the transfer, is received by agents of each of the three types. In state $b$, where $r(b)<i$ the bank will make a loss and the Treasury must tax the public in the amount $T(b)$ and use the resources to recapitalize the central bank. In this case, $T$ is a negative number and once again I assume that a lump-sum tax is feasible. 
Table 4: Asset Positions in Period 2 State $s$ with CB Intervention

\begin{tabular}{|c|c|c|c|c|}
\hline \multicolumn{2}{|c|}{ Type 1} & \multicolumn{3}{|c|}{ Type 2} \\
\hline $\mathrm{A}$ & $\mathrm{L}$ & \multicolumn{2}{|l|}{$\bar{A}$} & $\mathrm{~L}$ \\
\hline $\begin{array}{c}r(s)(E-\hat{E}) \\
\omega(s)+T(s) / 3\end{array}$ & $\begin{array}{c}i(B-\hat{B}) \\
N W_{1}(s)\end{array}$ & \multicolumn{2}{|c|}{$\begin{array}{c}i(B-\hat{B}) \\
\omega(a)+T(s) / 3\end{array}$} & $\begin{array}{c}r(s)(E-\hat{E}) \\
N W_{2}(a)\end{array}$ \\
\hline \multicolumn{2}{|c|}{ Type 3} & \multicolumn{3}{|c|}{ C. Bank } \\
\hline $\mathrm{A}$ & $\mathrm{L}$ & $\mathrm{A}$ & & $\mathrm{L}$ \\
\hline 0 & 0 & $r(s) \hat{E}$ & & $i \hat{B}$ \\
\hline$\Pi(s)+T(s) / 3$ & $N W_{3}(s)$ & $T(s)$ & $N W$ & ${ }_{C B}(s)=0$ \\
\hline
\end{tabular}

I have assumed, in constructing Table 4, that the tax-transfer scheme treats agents symmetrically. This is an important feature of any real world tax system since it is reasonable to assume that the government is unable to distinguish between agents of different types. An agent's type depends on private, unobservable characteristics. I will refer to a tax transfer policy that treats all agents in the same way as an anonymous policy.

An important consequence of the assumption of an anonymous tax-transfer policy, is that an open market equity purchase by the central bank has distributional effects. This follows from the fact that type 3 agents participate in the tax-transfer scheme but they are unable to participate in the period 1 financial market.

The following proposition demonstrates that the existence of distributional effects invalidates the assumption that central bank asset purchases will leave the relative prices $\omega(s)$ and $Q(s)$ unchanged.

Proposition 3 A central bank open market exchange of debt for equity, $f_{i-}$ nanced by anonymous lump sum taxes or transfers, will change the relative 
price of debt and equity.

This proposition is proved in Appendix B. The proposition establishes that central bank interventions in the financial markets are not irrelevant. But can they restore Pareto optimality? The answer, in this environment, is yes.

The optimal financial market position is one where $A_{1}(s)=0$ in both states. That position leads to an equilibrium in period 2 where $\omega(s)$ is the same across states, which is the requirement for optimal risk sharing in a world with no intrinsic risk. To mimic that position here, the central bank must stand ready to make any open market swap of debt for equity whenever the price of an equity contract is different from the price of a risk free bond. In practice, that policy could be implemented by buying a broad index fund of market securities and paying for the purchase through issuing short term Treasury debt.

Proposition 4 A policy where the central bank stands ready to purchase all private equity, whenever $Q(a) \neq Q(b)$ will restore Pareto Optimality. In equilibrium, this policy has the property that $E=\hat{E}=0$, and $B=\hat{B}=0$. Further, lump sum taxes and transfers in each state are equal to zero.

Proof. $Q(a)=Q(b)$ implies that $r(s)=i$ which is the pricing condition required for Pareto optimality in a world of no intrinsic uncertainty. From Proposition 1, the private demands and supplies of financial assets are equal to zero when this condition holds which implies that the net asset position of the central bank is given by the equations,

$$
\begin{aligned}
& \hat{E}=E=0, \\
& \hat{B}=B=0 .
\end{aligned}
$$

Since the central bank takes a zero net asset position, its net revenues and its net transfer to the private sector are also equal to zero. 
I have shown that it is possible to write down an economic model where an unconventional policy that stabilizes asset prices is Pareto improving. The skeptical reader may have a number of legitimate concerns before rushing to apply the policy in practice. The following section addresses some of these concerns.

\section{Qualitative easing in practice}

In this paper, I have abstracted from fundamental uncertainty. In the real world, there is a considerable amount of idiosyncratic uncertainty that would be expected to cancel out in aggregate by a simple application of the law of large numbers. But there are also correlated events that may cause aggregate stock market prices to fluctuate as a consequence of warranted optimism that new technologies may raise the prospects of higher profits in all future states.

Examples of fundamental aggregate shocks include the railroad boom of the mid nineteenth century, the invention of the telephone and the discovery of electricity in the late nineteenth century and the development of the automobile industry in the early twentieth century. In a world where there are legitimate reasons for the value of the stock market to fluctuate, a policy of equating the return on equity to the return on debt would not be the best one could hope for.

But although there are good reasons to think that stock market prices should fluctuate, Shiller (1981) and Leroy and Porter (1981) have shown that they fluctuate too much to be consistent with the observed price of future dividends. The central bank should not stabilize all asset price movements. But there are good reasons to think that some asset price movements are excessive. The dot-com boom of the 1990s and the housing boom of the 2000s were both predictable and predicted (Shiller, 2000, 2008) and they provide good examples of real world situations where an asset price stabilization policy could have prevented subsequent disaster. 
The reader may be concerned that, although I have provided a theoretical model where asset price stabilization is welfare improving, perhaps the environment has little or no connection with the real world. We have many examples of inefficiencies that can occur in theory but are not important in practice. For example, dynamic inefficiency is a logical possibility in a model of overlapping generations but Aiyagari $(1985,1988)$ has demonstrated that, as the length of life increases, the set of equilibria in an overlapping generations model shrinks to the allocation that would be achieved in a Ramsey growth model and Abel, Mankiw, Summers, and Zeckhauser (1989) have shown that dynamic inefficiency is not a good characterization of the U.S. economy. ${ }^{10}$ Hence, although dynamic inefficiency is a logical possibility, it appears not to be important in practice.

That is not the case in the model I have presented here. In new work, Farmer, Nourry, and Venditti (2012) show that the argument I have presented in this paper extends to an infinite horizon model of the kind popularized by Blanchard (1985), where agents die with constant probability. Our model does not rely on dynamic inefficiency and the inefficiencies that do occur do not disappear when the model is calibrated to realistic values for length of life and for rates of time preference of different agents. In that environment, the possibility that new agents may react differently in different states has real and important consequences for all existing agents.

\section{Conclusion}

An asset price stabilization policy is now under discussion as a result of the failure of traditional monetary policy to move the economy out of the current recession. Most of the academic literature sees the purchase of risky assets

\footnotetext{
${ }^{10}$ Dynamic inefficiency is a situation in which the real interest rate is less than the growth rate. Shell (1971) showed that dynamic inefficiency occurs in overlapping generations models because, although social wealth at equilibrium prices is unbounded, every individual agent has finite wealth.
} 
by the central bank as an alternative form of monetary policy. In this view, if a central bank asset policy works at all, it works by signalling the intent of future policy makers to keep interest rates low for a longer period than would normally be warranted, once the economy begins to recover. In my view, that argument is incorrect.

Central bank asset purchases have little if anything to do with traditional monetary policy. In some models, asset swaps by the central banks are effective because the central bank has the monopoly power to print money. Although that channel may play a secondary role when the interest rate is at the zero lower bound (Farmer, 2013), it is not the primary channel through which qualitative easing affects asset prices. Central bank open market operations in risky assets are effective because government has the ability to complete the financial markets by standing in for agents who are unable to transact before they are born and it is a policy that would be effective, even in a world where money was not needed as a medium of exchange.

I have made the case, in a recent series of books and articles (Farmer, 2006, 2010a,b,c,d, 2012, 2013), that qualitative easing matters. In this paper I have provided an economic model that shows why it matters. 


\section{Appendix A}

Proof of Proposition 1. Consider the function

$$
\psi(\omega, A)=\omega \zeta(\omega, A)=\Lambda \omega+A-\frac{1}{\alpha \omega^{1-\alpha}}
$$

which is continuous and satisfies the properties that $\psi \rightarrow-\infty$ as $\omega \rightarrow 0$ and $\psi \rightarrow+\infty$ as $\omega \rightarrow \infty$. These properties imply that for all $A \in R$, there is at least one value of $\omega \in(0, \infty)$ for which $\psi(\omega, A)=0$. Since $\psi$ is monotonically increasing in $\omega$, this value is unique. Since $\omega \neq 0$, it follows that a zero of $\psi(\omega, A)$ is also a zero of $\xi(\omega, A)$. Next we explore how $\omega$ depends on $A$. Since $\psi$ is monotonically increasing in $A$, it follows from the implicit function theorem that there exists a continuous, monotonically decreasing function $\tilde{f}: R \rightarrow R_{+}$, such that

$$
\omega=\tilde{f}(A)
$$

where

$$
\frac{\partial \tilde{f}(A)}{\partial A}=-\frac{\partial \psi / \partial A}{\partial \psi / \partial \omega}<0
$$

Notice that $\tilde{f}(A) \rightarrow 0$ as $A \rightarrow+\infty$, and $\tilde{f}(A) \rightarrow+\infty$ as $A \rightarrow-\infty$. Now define

$$
g(A)=\frac{A}{f(A)}
$$

where, from the properties of $\tilde{f}, g$ is continuous, monotonically increasing and $g(A) \rightarrow+\infty$ as $A \rightarrow+\infty$, and $g(A) \rightarrow-\infty$ as $A \rightarrow-\infty$. Using the labor supply equation, (12) and the definition of $A$, (4), it follows that agent 1 supplies $n_{1}$ units of labor, where

$$
n_{1}=\lambda_{1}-\frac{\left(1-\lambda_{1}\right)}{\lambda_{1}-\lambda_{2}} g(A) \leq 1
$$


Recall that $\lambda_{1}>\lambda_{2}$. Rearranging (58), follows that there is an lower bound on $A, A^{L}<0$, that is a solution to the equation

$$
g\left(A^{L}\right)=-\left(\lambda_{1}-\lambda_{2}\right) .
$$

The existence of this solution follows from the inverse function theorem. A symmetric argument shows that there is an upper bound on $A, A^{U}>0$. This follows from the inequality,

$$
n_{2}=\lambda_{2}+\frac{\left(1-\lambda_{2}\right)}{\lambda_{1}-\lambda_{2}} g(A) \leq 1,
$$

which implies

$$
g\left(A^{U}\right)=\left(\lambda_{1}-\lambda_{2}\right) .
$$

The function $f$ in Proposition 1 is the function $\tilde{f}$ restricted to the domain $\left[R^{L}, R^{U}\right]$

\section{Appendix B}

Proof of Proposition 3. From Proposition 1; the equilibrium real wage in state $s$, is an increasing function of the net asset position of an agent of type 1 ,

$$
\omega=f(A),
$$

where $A=\left(\lambda_{1}-\lambda_{2}\right) A_{1}$. Suppose, counterfactually, that the open market purchase by the central bank is irrelevant. Define $\Delta N W_{1}(s)$ to be the change in the net worth of type 1 agents in state $s$, as a consequence of the central bank open market operation. $\Delta N W_{1}(s) \equiv \Delta A_{1}(s)$ is given by the expression

$$
\Delta A_{1}(s)=-r(s) \hat{E}+i \hat{B}+\frac{T(s)}{3}=0 .
$$


From the requirement that the intervention be funded from lump sum taxes or transfers we have that $T(s)$ is equal to

$$
T(s)=r(s) \hat{E}(s)-i(s) \hat{B}(s),
$$

from which it follows that

$$
\Delta A_{1}(s)=\frac{2}{3}(r(s) \hat{E}(s)-i(s) \hat{B}(s)) .
$$

Since, by assumption, the initial equilibrium was one where sunspots matter, and hence $r(s) \neq i$, the intervention cannot leave the net asset position unchanged. But from Proposition 2, the real wage is a monotonically increasing function of $A(s)$ and from Equation (36), the price of an Arrow security is a function of the real wage. It follows that the real wage and the prices of debt and equity cannot remain invariant to a central bank open market operation. 


\section{References}

Abel, A. B., N. G. Mankiw, L. H. Summers, and R. J. Zeckhauser (1989): "Assesing Dynamic Efficiency: Theory and Evidence," Review of Economic Studies, 56, 1-20.

AiyagaRI, S. R. (1985): "Observational Equivalence of the Overlapping Generations and the Discounted Dynamic Programming Frameworks fror One-sector Growth," Journal of Economic Theory, 35, 202-221.

(1988): "Nonmonetary Steady States in Stationary Overlapping Generations Models with Long Lived Agents and Discounting: Multiplicity, Optimality and Consumption Smoothing," Journal of Economic Theory, 45, 102-127.

Blanchard, O. J. (1985): "Debt, Deficits, and Finite Horizons," Journal of Political Economy, 93(April), 223-247.

Buiter, W. H. (2008): "Quantitative easing and qualitative easing: a terminological and taxonomic proposal," Financial Times, Willem Buiter's mavercon blog.

(2010): Reversing unconventional monetary policy: technical and political considerationschap. 3, pp. 23-42. SUERF - The European Money and Finance Forum.

Cass, D., And K. Shell (1983): "Do Sunspots Matter?," Journal of Political Economy, 91, 193-227.

D'Amico, S., And T. B. King (2010): "Flow and Stock Effects of LargeScale Treasury Purchases," Finance and Economics Discussion Series Division of Research and Statistics and Monetary Affairs, Federal Reserve Board Washington D.C., Paper, 2010-52. 
Eggertsson, G. B., and M. Woodford (2002): "The zero bound on interest rates and optimal monetary policy," Brookings Papers on Economic Activity, 2, 139-211.

Farmer, R. E. A. (2006): "Old Keynesian Economics," UCLA mimeo., Paper presented at a conference in honor of Axel Leijonhufvud, held at UCLA on August 30th 2006.

- (2010a): Expectations, Employment and Prices. Oxford University Press, New York.

(2010b): How the Economy Works: Confidence, Crashes and Selffulfilling Prophecies. Oxford University Press, New York.

- (2010c): "How to Reduce Unemployment: A New Policy Proposal,", Journal of Monetary Economics: Carnegie Rochester Conference Issue, $57(5), 557-572$.

- (2010d): "We Need More Quantitative Easing to Create Jobs," Financial Times.

_ (2012): "Central Banks Should Do Much More," Financial Times.

- (2013): "The effect of conventional and unconventional monetary policy rules on inflation expectations: theory and evidence.," Oxford Review of Economic Policy, In Press.

Farmer, R. E. A., C. Nourry, and A. Venditti (2012): "Why Sunspots Really Do Matter," UCLA mimeo.

Gagnon, J. E. (2012): "Michael Woodford's Unjustified Skepticism on Portfolio Balance (A Seriously Wonky Rebuttal)," Avaialable online at: http://www.piie.com/blogs/realtime/?p=3112. 
Gagnon, J. E., M. Raskin, J. Remache, and B. Sack (2011): "The Financial Market Effects of the Federal Reserve's Large Scale Asset Purchases," International Journal of Central Banking, 7(1), 3-43.

Hamilton, J. D., and J. C. Wu (2012): "The Effectiveness of Alternative Monetary Policy Tools in a Zero Lower Bound Environment," Journal of Money Credit and Banking, 44(1), 3-46.

Jevons, W. S. (1878): "Commercial crises and sun-spots," Nature, xix, $33-37$.

Krishnamurthy, A., And A. Vissing-Jorgensen (2011): "The effects of quantitative easing on interest rates: channels and implications for policy," Brookings papers on economic activity, Fall, In Press.

Krugman, P. R. (1998): "It's Baaack: Japan's Slump and the Return of the Liquidity Trap," Brookings Papers on Economic Activity, pp. 137-206.

Leroy, S., and R. Porter (1981): "Stock Price Volatitlity: A Test based on Implied Variance Bounds," Econometrica, 49, 97-113.

Li, C., And M. Wei (2012): "Term Structure Modelling with Supply Factors and the Federal Reserve's Large Scale Asset Purchase Programs," Federal Reserve Board mimeo.

Neely, C. J. (2010): "The Large-Scale Asset Purchases Had Large International Effects," Economic Research, Federal Reserve Bank of St. Louis, Working Paper 2010-018D.

Shell, K. (1971): "Notes on the Economics of Infinity," Journal of Political Economy, 79, 1002-1011.

Shiller, R. J. (1981): "Do stock prices move too much to be justified by subsequent changes in dividends?," American Economic Review, 71, 421436 . 
— (2000): Irrational Exuberance. Princeton University Press.

- (2008): The Subprime Solution: How Today's Financial Crisis Happened, and What to Do about it. Princeton University Press.

Tobin, J. (1963): "An Essay on the Principles of Debt Management," in Fiscal and Debt Management Policies, ed. by C. o. M. a. Credit, pp. 143218. Prentice-Hall, Englewood Cliffs, NJ.

- (1969): "A General Equilibrium Approach to Monetary Theory," Journal of Money, Credit and Banking, 14(May), 15-29.

Wallace, N. (1981): "A Modigliani-Miller Theorem for Open-Market Operations," American Economic Review, 71(June), 267-274.

Woodford, M. (2012): "Methods of Policy Accommodation at the InterestRate Lower Bound," Columbia University mimeo, Paper presented at the Jackson Hole Symposium, "The Changing Policy Landscape," August 31September 1, 2012. 